\title{
Connective Tissue Growth Factor Participates in Scar Formation of Crescentic Glomerulonephritis
}

\author{
Katsuyoshi Kanemoto, Joichi Usui, Shinsuke Tomari, Hideki Yokoi, \\ Masashi Mukoyama, Jan Aten, Jan J. Weening, and Michio Nagata \\ Department of Pathology (KK, JU, ST, MN), Institute of Basic Medical Sciences, University of Tsukuba, Tsukuba, \\ Ibaraki, Department of Medicine and Clinical Science (HY, MM), Kyoto University, Kyoto, Japan; and Department \\ of Pathology Academic Medical Center (JA, JJW), University of Amsterdam, Amsterdam, the Netherlands
}

\begin{abstract}
SUMMARY: Glomerular crescents are a major determinant of progression in various renal diseases. Some types of growth factors are known to be involved in the evolution of crescents and the subsequent scar formation. Although glomerular parietal epithelial cells (PECs) are the major component of cellular crescents, the influence of growth factors on PECs is unknown. We performed immunohistochemical studies and in situ hybridization to examine alterations in connective tissue growth factor (CTGF) expression and to identify CTGF-synthesizing cells in crescents in the crescentic glomerulonephritis model of Wistar Kyoto rats. In addition, we examined the roles of fibroblast growth factor (FGF)-2, platelet-derived growth factor (PDGF)-BB, transforming growth factor (TGF)- $\beta$, and CTGF in cell proliferation and matrix synthesis in an established rat PEC cell line (PEC line). In an acute phase of rat crescentic glomerulonephritis, a major component of the crescents were macrophages, which did not express CTGF mRNA. However, in the advanced phase, crescents strongly expressed CTGF mRNA and the epithelial marker pan-cadherin but did not express the macrophage marker ED1, suggesting that PECs synthesized the CTGF. In the PEC line, FGF-2 predominantly promoted $\left[{ }^{3} \mathrm{H}\right]$ thymidine incorporation compared with PDGF-BB. Both TGF- $\beta$ and PDGF-BB strongly stimulated extracellular matrix synthesis in association with up-regulation of endogenous CTGF, but TGF- $\beta$ showed a predominant role. FGF- 2 had a minor effect on it. In addition, blockade of endogenous CTGF using an antisense oligodeoxynucleotide significantly attenuated both TGF- $\beta$ - and PDGF-BB-induced extracellular matrix synthesis. These results suggest that several growth factors promote cell proliferation and matrix production in PECs. CTGF-mediated matrix production via the TGF- $\beta$ or PDGF-BB pathway in PECs may, in part, play a role in the progression of scar formation in crescents. (Lab Invest 2003, 83:1615-1625).
\end{abstract}

$G$ lomerular crescents are one of the most important, but nonspecific, pathologic features predicting renal prognosis, irrespective of the native kidney disease (Jennette, 1998). It has been shown that the incidence of crescent formation in biopsy specimens correlates well with the clinical outcome (Morrin et al, 1978; Whitworth et al, 1976). Although the initial cellular crescents are composed of macrophages and parietal epithelial cells (PECs; Bowman's epithelial cells), many studies have demonstrated that the predominant cellular component in the advanced stage of crescents is epithelial histogenesis, rather than macrophages (Guettier et al, 1986; Harrison and Macdonald, 1986; Kondo et al, 1972; Magil, 1985; Nagata, 2000; Yoshioka et al, 1987).

It is well known that cellular crescents frequently undergo fibrous scarring or segmental sclerosis by synthesis and deposition of extracellular matrix (ECM).

DOI: 10.1097/01.LAB.0000096711.58115.46

Received August 8, 2003.

This work was supported in part by grants from the University of Tsukuba; Showa University; and the Ministry of Health, Labor, and Welfare of Japan (research on specific diseases of nephro-urological study group). Address reprint requests to: Dr. Michio Nagata, Department of Pathology, Institute of Basic Medical Sciences, University of Tsukuba, Tsukuba, Ibaraki,305-8575, Japan.E-mail:nagatam@md.tsukuba.ac.jp
In fact, studies on experimental crescentic glomerulonephritis (CRGN) have demonstrated that PECs may potentially contribute to the production of ECM proteins through the process of transdifferentiation into myofibroblast-type cells (Fujigaki et al, 2002; Ng et al, 1999). Thus, PECs represent one of the important cell types in scar formation of crescents.

Some types of growth factors and inflammatory cytokines may be involved in the evolution of crescents and subsequent scar formation. Among them, platelet-derived growth factor (PDGF)-BB, basic fibroblast growth factor (FGF)-2, and transforming growth factor (TGF)- $\beta$ have been speculated to be involved in crescent formation by histologic studies on anti-glomerular basement membrane (GBM) glomerulonephritis (Fujigaki et al, 2001; Lianos et al, 1997; $\mathrm{Ng}$ et al, 1999). Moreover, TGF- $\beta$ receptors, PDGF receptor $\beta$, and FGF receptor 1 have been shown to be expressed in PECs and crescents in humans (Alpers et al, 1993; Floege et al, 1999; Matsuda et al, 1997; Yamamoto et al, 1998).

CTGF, originally isolated from the conditioned media of HUVEC, belongs to a new family of cysteine-rich growth factors (Bork, 1993; Bradham et al, 1991). Ito and co-workers $(1998,2001)$ demonstrated that CTGF mRNA is mainly expressed in podocytes and PECs in human and rat glomeruli. In addition, CTGF is localized in proliferative and fibrotic glomerular lesions in 

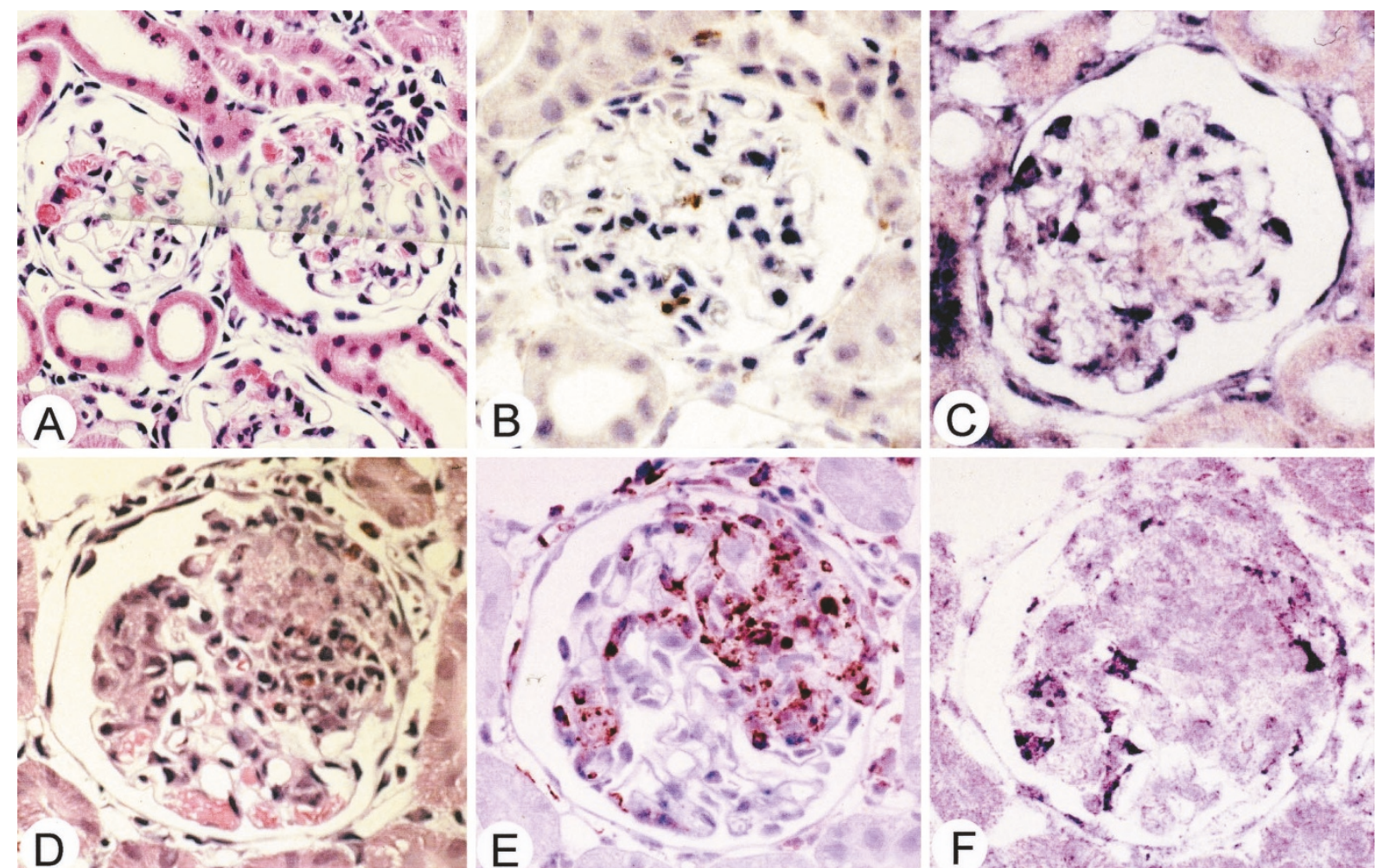

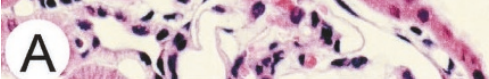
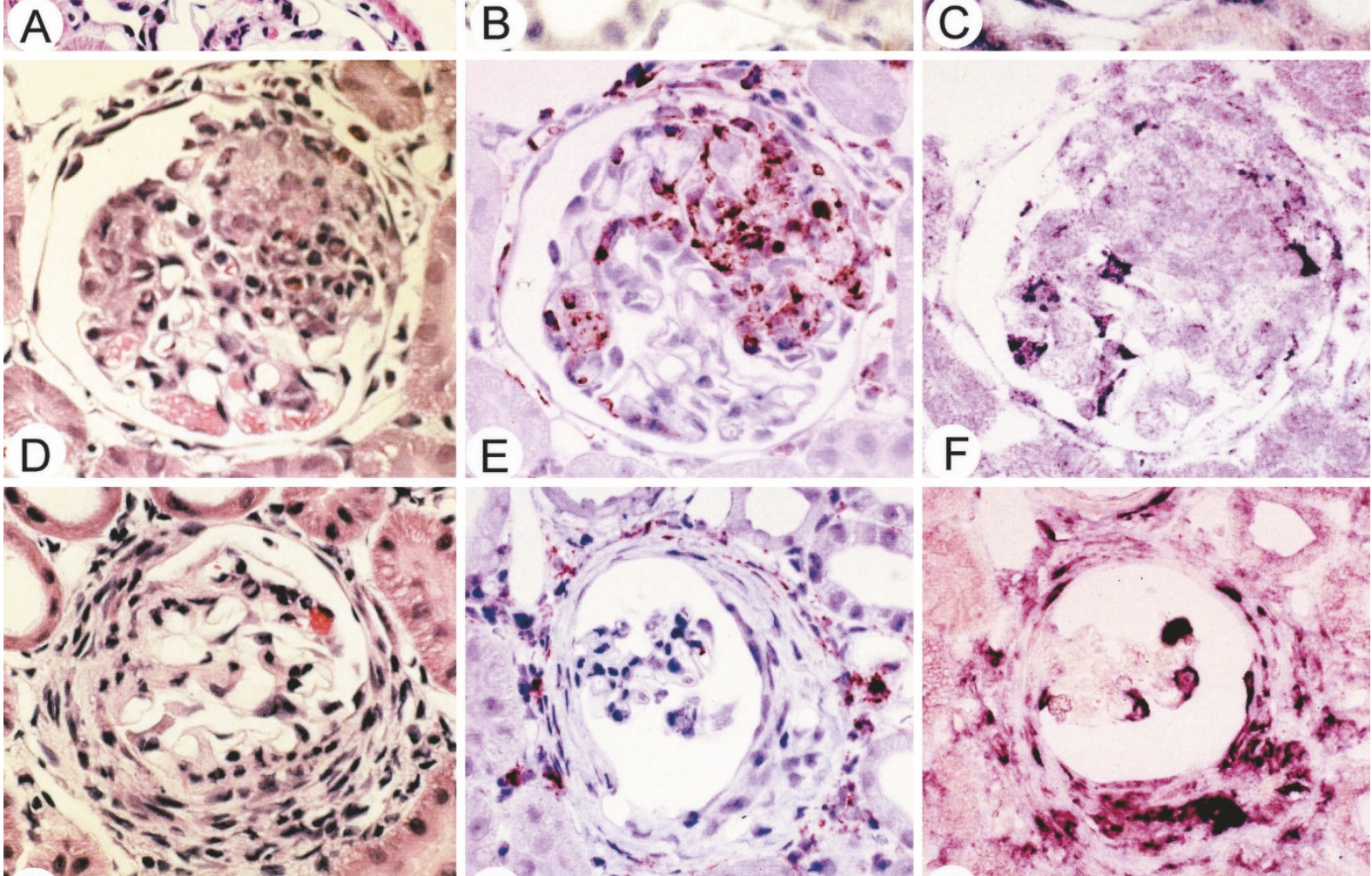

$G=1-\sin ^{2}=$
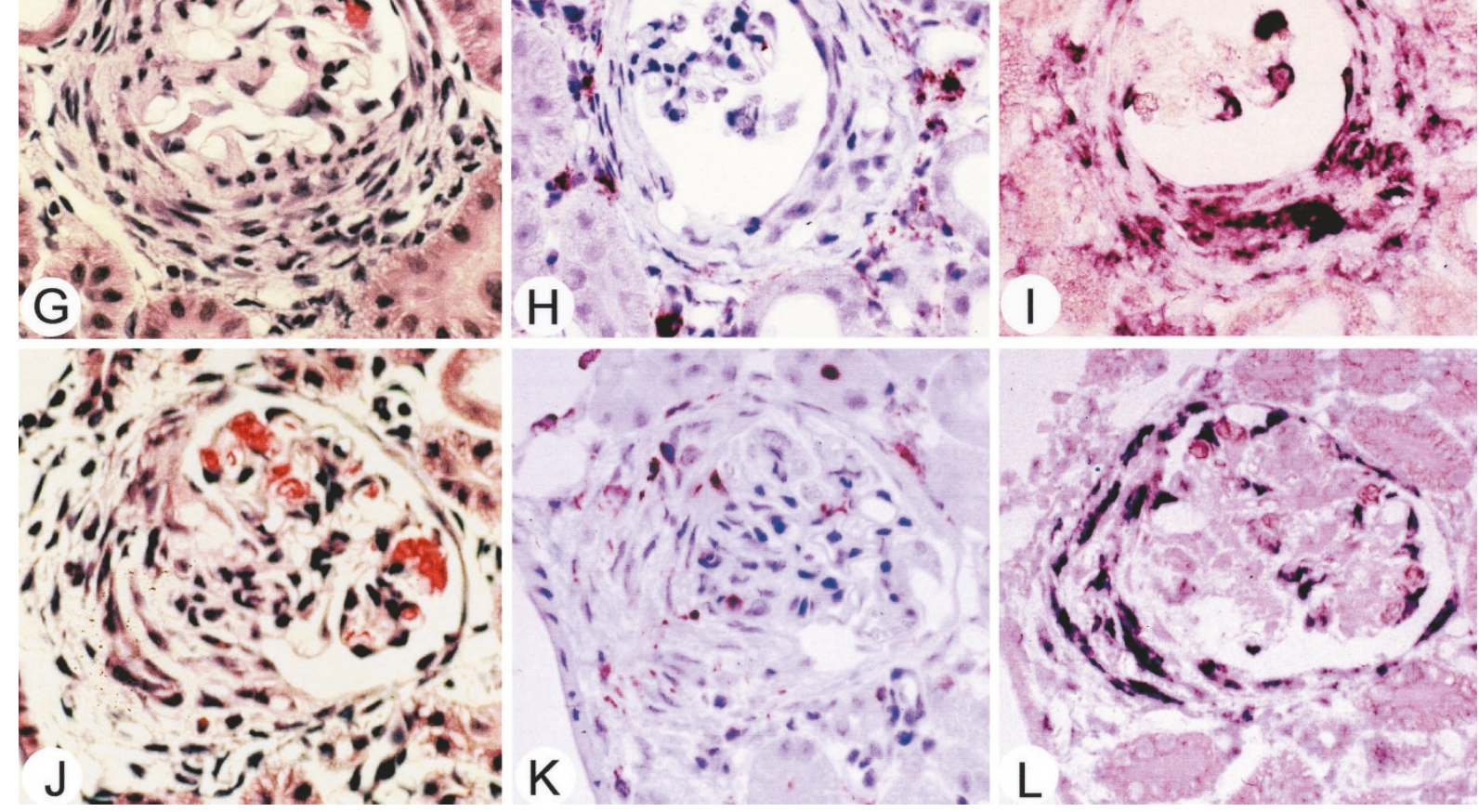

Figure 1.

Photomicrographs of glomeruli from anti-glomerular basement membrane nephritis in Wistar Kyoto rats. (A to C) Control rats at 4 days. Normal glomeruli (A) include minimal ED1-positive cells in the capillary lumens (B). Connective tissue growth factor (CTGF) mRNA is expressed in podocytes and parietal cells (C). (D to F) An initial cellular crescent at 4 days (serial sections). The cellular crescent (D) is mostly composed of ED1-positive cells (E), but these do not generally express CTGF mRNA (F). ( $G$ to I) A cellular crescent at 7 days (serial sections). The cellular crescent $(G)$ is negative for ED1 (H) and strongly expresses CTGF mRNA (I). (J to L) A fibrocellular crescent at 14 days (serial sections). The fibrocellular crescent $(\mathrm{J})$ is virtually negative for ED1 (K) and expresses CTGF mRNA, the same as the cellular crescent $(L)(A, \times 200$; B to $L, \times 400)$. 
Table 1. The Percentage of Glomerulus with Crescent Formation and CTGF mRNA Score in Anti-GBM WKY Rats $(\text { Mean } \pm \mathrm{sD})^{a}$

\begin{tabular}{|c|c|c|c|c|c|c|c|}
\hline Induction & $\begin{array}{l}\% \text { Crescent formation in } \\
\text { counted glomeruli }\end{array}$ & $\begin{array}{c}\% \text { Cellular in counted } \\
\text { crescents }\end{array}$ & $\%$ Fibrocellular & $\%$ Fibrous & $\begin{array}{l}\text { CTGF mRNA } \\
\text { score }^{b}\end{array}$ & $\begin{array}{l}\text { ED1 } \\
\text { score }^{b}\end{array}$ & $n$ (Control) \\
\hline 4 days & $19.0 \pm 5.7 \%$ & $97.9 \pm 0.8 \%$ & $2.1 \pm 1.5 \%$ & $0.0 \%$ & $0.25 \pm 0.127$ & $1.55 \pm 0.287$ & $5(4)$ \\
\hline 7 days & $43.5 \pm 5.8 \%$ & $77.5 \pm 6.3 \%$ & $19.3 \pm 5.5 \%$ & $2.8 \pm 1.2 \%$ & $1.16 \pm 0.16 \underset{7}{\rfloor}$ & $0.75 \pm 0.21 \underset{\downarrow}{\lrcorner}$ & $5(4)$ \\
\hline 14 days & $55.5 \pm 5.3 \%$ & $65.1 \pm 5.8 \%$ & $34.8 \pm 4.2 \%$ & $5.4 \pm 3.0 \%$ & $1.51 \pm 0.28$ & $0.41 \pm 0.17$ & $5(3)$ \\
\hline
\end{tabular}

CTGF, connective tissue growth factor; GBM, glomerular basement membrane; WKY, Wistar Kyoto.

${ }^{a}$ Data pooled from anti-GBM nephritis WKY rats $(n=5$ in each day). More than 300 glomeruli were counted in each rat.

${ }^{b}$ CTGF mRNA score and ED1 score were estimated in each of at least 50 glomerular crescents per rat (0, negative; 1 and 2, according to staining intensity).

* Statistical difference is $p<0.01$.

experimental and human renal diseases, including human CRGN (Ito et al, 1998, 2001). From these studies, it can be surmised that CTGF participates in the progression of glomerular scarring in crescents, yet the CTGF-expressing cells in cellular crescents and the regulation of CTGF interactions with these growth factors remain obscure. Due to the lack of an appropriate PEC line, cell biological studies on the regulation of PEC proliferation and ECM synthesis have not been widely performed.

In the present study, we used a rat model of CRGN to examine alterations in CTGF gene expression during progressive scar formation in crescents. In addition we investigated the roles of growth factors including FGF-2, PDGF-BB, TGF- $\beta$, and CTGF in cell proliferation and ECM synthesis in an established cell line of rat PECs (PEC line) that has a similar phenotype to Bowman's epithelium in vivo. Our results indicate that the cells expressing CTGF in crescents are likely to be PECs, and not infiltrating macrophages, in the rat CRGN model. Moreover, FGF-2 predominantly stimulated cell proliferation, while both PDGF-BB and TGF- $\beta$ mediated upregulation of CTGF participating in ECM production in the PEC line. These growth factor interactions with PECs seem to be one of the important mechanisms of disease progression in CRGN.

\section{Results}

\section{Crescents Express CTGF mRNA}

In the glomeruli of control rats, only a few ED1-positive cells were included in the capillaries (Fig. 1, A and B). The epithelial marker pan-cadherin was expressed among the PECs (data not shown). CTGF mRNA expression was limited to podocytes and PECs (Fig. 1C). Four days after disease induction, a distinct fraction of the glomeruli $(19.0 \pm 5.7 \%$, Table 1) revealed crescent formation (Fig. 1D). The majority of glomeruli with crescents at this stage were accompanied by segmental endocapillary proliferation with tuft necrosis and fibrin deposition. Cellular crescents in this stage were composed of ED1-positive cells (score $1.55 \pm 0.28$, Fig. $1 \mathrm{E}$ ), but the epithelial marker pancadherin was only faintly detected (data not shown). Crescents with predominant ED1-positive cells only faintly expressed CTGF mRNA (score $0.25 \pm 0.12$, Fig.
1F). At Day 7, the percentage of crescents apparently increased (43.5 $\pm 5.8 \%$, Fig. 1G). Cellular crescents began to express pan-cadherin (data not shown) with CTGF mRNA (score $1.16 \pm 0.16$, Fig. 1l). Of note, serial sections revealed that CTGF mRNA-positive crescents barely expressed ED1 (score $0.75 \pm 0.21$, Fig. 1H). At Day 14, more than half the glomeruli showed pronounced crescent formation (55.5 \pm $5.3 \%$ ), and the percentage of fibrocellular crescents increased (34.8 $\pm 4.2 \%$, Fig. 1J). ED1-positive cells apparently disappeared from the crescents (score $0.41 \pm 0.17$, Fig. $1 \mathrm{~K}$ ). In this phase, CTGF mRNA was strongly expressed in the crescents (score $1.51 \pm$ 0.28 , Fig. $1 \mathrm{~L}$ ). Synaptopodin was virtually absent from the crescents (data not shown).

\section{The PEC Line Expressed the Characteristic In Vivo Phenotype}

The cultured rat PEC line was polygonal, with a cobblestone-like appearance. Immunofluorescence showed that the cells were positive for pan-cadherin, WT1, Pax-2, cytokeratin, and vimentin (Fig. 2). PGP9.5, recently recognized as a specific marker for rat PECs, was also positive. In contrast, the cells were exclusively negative for podocyte markers, including synaptopodin, podocalyxin, and a tubular cell marker, peanut lectin. An endothelial cell marker, von Willebrand factor, was absent (data not shown).

\section{FGF-2 Exerted a Strong Effect on Cell Proliferation in the PEC Line}

Administration of FGF-2 or PDGF-BB ( 0 to $50 \mathrm{ng} / \mathrm{ml}$ ) to the PEC line dose-dependently stimulated the incorporation of $\left[{ }^{3} \mathrm{H}\right]$ thymidine (Fig. 3). However, the increasing ratio of $\left[{ }^{3} \mathrm{H}\right]$ thymidine incorporation in FGF-2 ( 2.5 to $20 \mathrm{ng} / \mathrm{ml}$ ) was significantly higher than that in PDGF-BB $(p<0.01)$. It appeared that FGF-2 already had a strong effect on promoting $\left[{ }^{3} \mathrm{H}\right]$ thymidine incorporation at low doses (2.5 to $5 \mathrm{ng} / \mathrm{ml})$.

\section{ECM Protein Synthesis Was Associated with CTGF and p27 Up-regulation}

The PEC line displayed accelerated ECM protein synthesis while the cells were fully-confluent, accompa- 

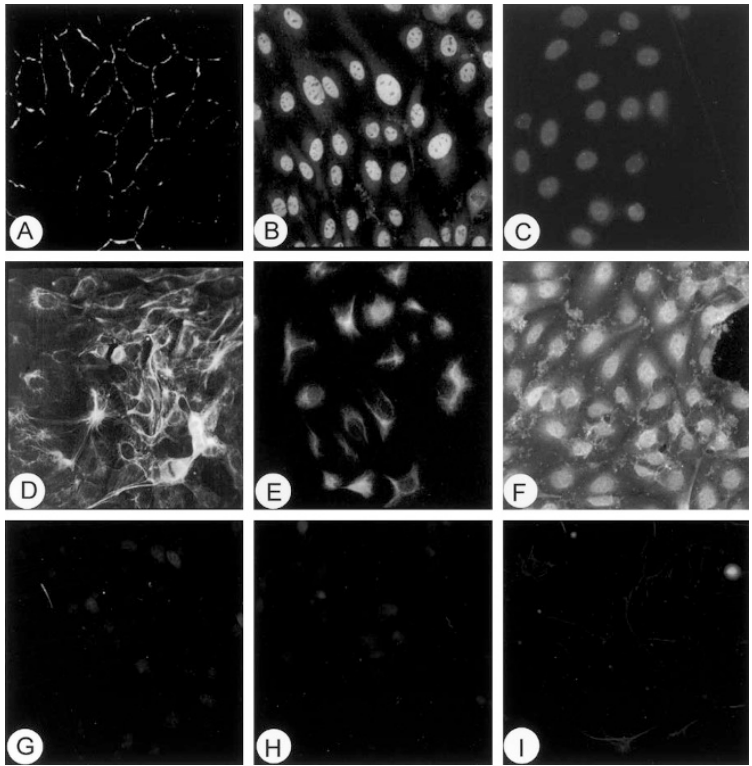

Figure 2.

Phenotypic characteristics of the rat parietal epithelial cell (PEC) line. The rat PEC line shows positive staining for pan-cadherin (A), WT1 (B), Pax-2 (C), cytokeratin (D), vimentin (E), and PGP9.5 (F). The cells are negative for synaptopodin $(G)$, podocalyxin $(H)$, and peanut lectin $(I) . \times 400$.

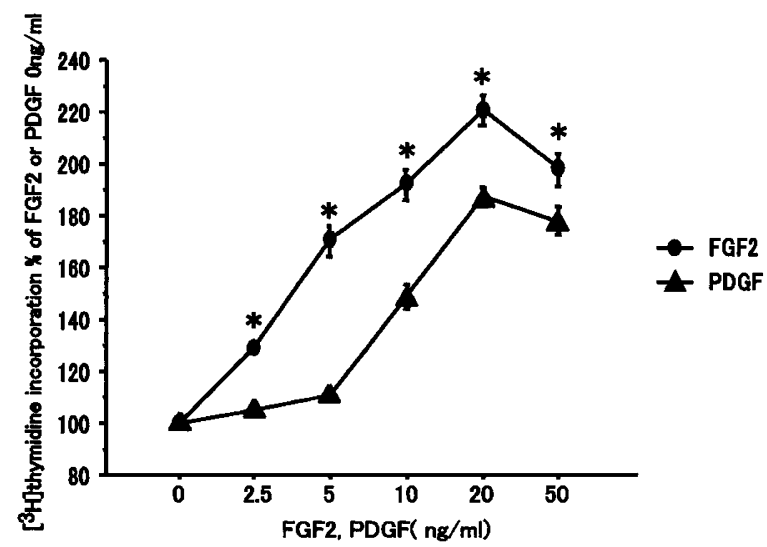

\section{Figure 3.}

Effects of fibroblast growth factor (FGF)-2 and platelet-derived growth factor (PDGF)-BB on $\left[{ }^{3} \mathrm{H}\right]$ thymidine incorporation in the cultured rat parietal epithelial cell (PEC) line. FGF-2 and PDGF-BB (0 to $20 \mathrm{ng} / \mathrm{ml}$ ) dose-dependently increase $\left[{ }^{3} \mathrm{H}\right]$ thymidine incorporation. FGF-2 is more effective at promoting $\left[{ }^{3} \mathrm{H}\right]$ thymidine incorporation in the PEC line than PDGF-BB (range, 2.5 to $20 \mathrm{ng} / \mathrm{ml}$ ). Values are means \pm SD of four independent cultures, and the statistical significance is ${ }^{*} p<0.01$ PDGF-BB vs FGF-2.

nied by increased expression of the cell cycle inhibitor p27 and repression of CDK2, as shown by Western blotting analysis (Fig. 4A). CTGF mRNA expression was clearly increased when the cells were sub- or fully confluent, compared with when they were nonconfluent (subconfluent, $2.65 \pm 0.15$-fold; fully confluent, $3.66 \pm 0.17$-fold of nonconfluent, $p<0.01$ ) (Fig. 4B), as shown by RT-PCR. In addition, CTGF mRNA expression was concurrent with the up-regulation of p27 (Fig. 4B).

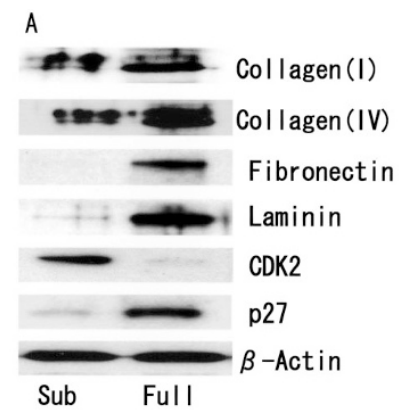

B
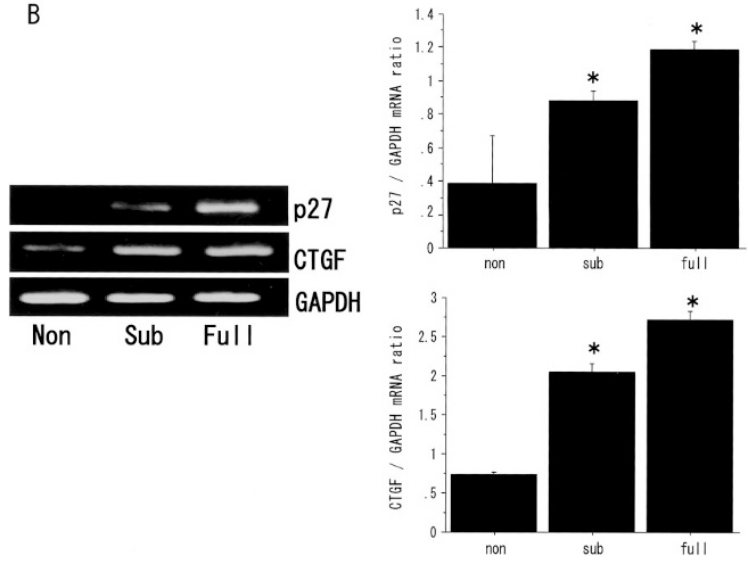

Figure 4

Expression of extracellular matrix (ECM) proteins, cell cycle proteins, and connective tissue growth factor (CTGF) mRNA at different confluencies. (A) Western-blotting. ECM is increased at full-confluency, accompanied by p27 up-regulation, compared with subconfluency. Western blotting was independently performed five times, and representative data of one experiment are shown. (B) RT-PCR. The increase in cell density results in up-regulation of CTGF mRNA with p27. The graphs represent semiquantification of the p27 and CTGF expression, as compared with the GAPDH expression. Values are means $\pm S D$, and the statistical significance is ${ }^{*} p<0.01$. RT-PCR was independently performed four times, and representative results of one experiment are shown. The quantitative data are described in the text.

\section{Both PDGF-BB and TGF- $\beta$ Stimulated ECM Protein Synthesis with Endogenous CTGF Up-regulation}

Both FGF-2 and PDGF-BB (0 to $50 \mathrm{ng} / \mathrm{ml}$ ) appeared to increase the synthesis of all ECM proteins examined in the PEC line by Western blotting analysis (data not shown). However, PDGF-BB revealed more apparent effects than FGF-2 on the synthesis of all four ECM proteins, especially at low doses of administration (2.5 to $10 \mathrm{ng} / \mathrm{ml}$, data not shown). In addition, PDGF-BB appeared to stimulate CTGF mRNA expression more than FGF-2 at all doses tested (data not shown). We then performed a comparative analysis of TGF- $\beta-$, FGF-2-, and PDGF-BB-mediated ECM synthesis via CTGF up-regulation in the PEC line, because CTGF has been considered to be a master downstream mediator of the profibrotic actions of TGF- $\beta$. Figure $5 \mathrm{~A}$ and $B$ show the effects of FGF-2, PDGF-BB, and TGF- $\beta$ ( 5 and $10 \mathrm{ng} / \mathrm{ml}$ ) on CTGF mRNA expression in the PEC line, as shown by semiquantitative RT-PCR. TGF- $\beta$ appeared to stimulate more CTGF expression than PDGF-BB $(p<0.05)$ or FGF-2 $(p<0.01)$. In the Western blotting analysis for ECM synthesis (Fig. 5C), 
A

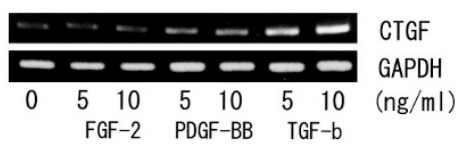

B

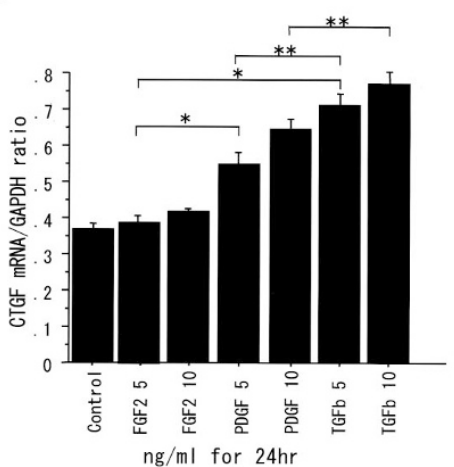

C

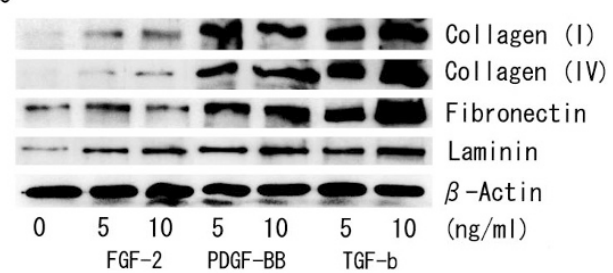

Figure 5 .

Comparative analyses of connective tissue growth factor (CTGF) mRNA expression and extracellular matrix (ECM) synthesis between fibroblast growth factor (FGF)-2, platelet-derived growth factor (PDGF)-BB, and transforming growth factor (TGF)- $\beta$ in the parietal epithelial cell (PEC) line. (A) RT-PCR. TGF- $\beta$ shows more endogenous CTGF mRNA expression than FGF-2 or PDGF-BB. Representative results of one experiment are shown. (B) Semiquantitative analysis of CTGF mRNA expression compared with GAPDH. TGF- $\beta$ increases CTGF mRNA expression more than FGF-2 $(p<0.01)$ or PDGF-BB $(p<0.05)$. Values represent means \pm SD of four independent RT-PCRs, and the statistical significance is ${ }^{*} p<0.01$ or ${ }^{* *} p<0.05$. (C) Western blotting. TGF- $\beta$ apparently increases ECM synthesis in the PEC line compared with the control $(0 \mathrm{ng} / \mathrm{ml})$ and FGF-2. Note that PDGF-BB seems to increase ECM synthesis to a similar extent to TGF- $\beta$. Western blotting was independently performed four times, and representative data from one experiment are shown.

TGF- $\beta$ revealed apparent effects on the synthesis of all four ECM proteins tested, similar to PDGF-BB.

\section{CTGF Antisense Oligodeoxynucleotide (ODN) Suppressed ECM Protein Synthesis in the PEC Line}

To further examine the significance of CTGF-mediated ECM synthesis and its regulation by PDGF-BB or TGF- $\beta$, endogenous CTGF was blocked by phosphorothioate antisense ODN. The CTGF antisense ODN effectively inhibited endogenous CTGF mRNA expression as revealed by RT-PCR (Fig. 6A), thereby verifying the effectiveness of this method. The CTGF antisense ODN suppressed the synthesis of all of the ECM proteins tested in the PDGF- or TGF- $\beta$-stimulated PEC line (Fig. 6B). Figure 6C shows the semiquantitative estimation of the ratios of ECM protein expression by Western blotting analysis. All of the ECM protein expressions tested were significantly reduced by the CTGF antisense ODN under stimulation with PDGF-BB (type I collagen, $0.36 \pm 0.20$-fold; type IV collagen, $0.40 \pm 0.18$-fold; fibronectin, $0.26 \pm 0.18-$ fold; and laminin, $0.43 \pm 0.20$-fold of PDGF-BB [20 $\mathrm{ng} / \mathrm{ml}$-stimulated cells) or TGF- $\beta$ (type I collagen, $0.25 \pm 0.13$-fold; type IV collagen, $0.21 \pm 0.10$-fold; fibronectin, $0.20 \pm 0.15$-fold; and laminin, $0.19 \pm$ 0.10 -fold of TGF- $\beta$ [10 ng/ml]-stimulated cells).

\section{Discussion}

It has been demonstrated that CTGF is expressed in the crescents in human glomerulonephritis (Ito et al, 1998). As evidence of the types of cells synthesizing CTGF, the present study showed that CTGF mRNA was expressed in the crescents with PEC proliferation at 7 and 14 days after injection in a rat progressive model of CRGN. Of note, CTGF was scarcely expressed in macrophage-predominant crescents at 4 days after injection. These findings suggest that PECs synthesize CTGF, whereas inflammatory cells are not a major source of CTGF in cellular crescents. Considering the functions of CTGF, it is likely that the PEC-synthesized CTGF participates in scar formation in crescents.

The evolution of cellular crescents generally requires endocapillary proliferation, including an influx of inflammatory cells with GBM breakage resulting in PEC proliferation (Guettier et al, 1986; Jennette, 1998; Kondo et al, 1972; Whitworth et al, 1976). It has been suggested that several inflammatory cytokines and growth factors are involved in PEC proliferation. It is known that PECs express PDGF receptor $\beta$, FGF receptor 1 , and TGF- $\beta$ receptors in vivo (Alpers et al, 1993; Floege et al, 1999; Matsuda et al, 1997; Yamamoto et al, 1998). Moreover, FGF-2 and PDGF-BB have been immunohistochemically localized in the crescents of anti-GBM nephritis in Wistar Kyoto rats (Fujigaki et al, 2001; Lianos et al, 1997). Growth factor-mediated PEC proliferation has been postulated in experimental glomerulonephritis. Sasaki and co-workers (1997) reported that FGF-2 released from injured podocytes may act on PECs to induce cell proliferation in experimental nephrosis. Floege et al (1993) reported that injured podocytes also produce PDGF-BB, which has the possibility of contributing to the proliferation of PECs. Thus, it can be surmised that FGF-2, PDGF-BB, TGF- $\beta$, and CTGF are involved in 
A

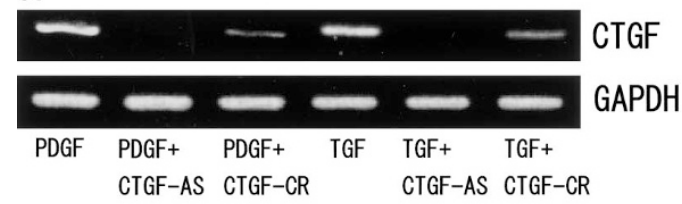

B

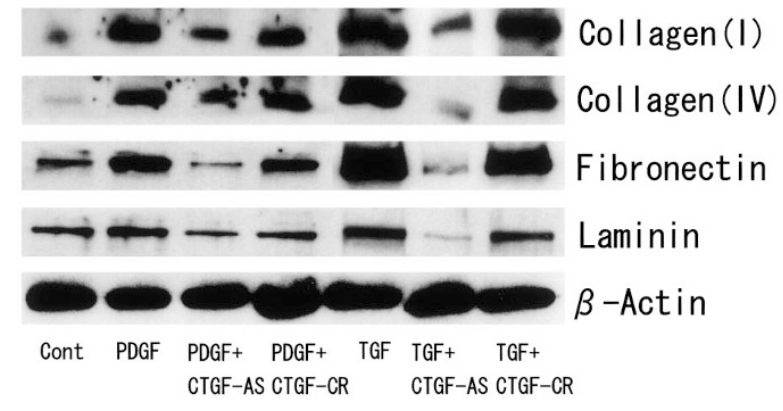

c
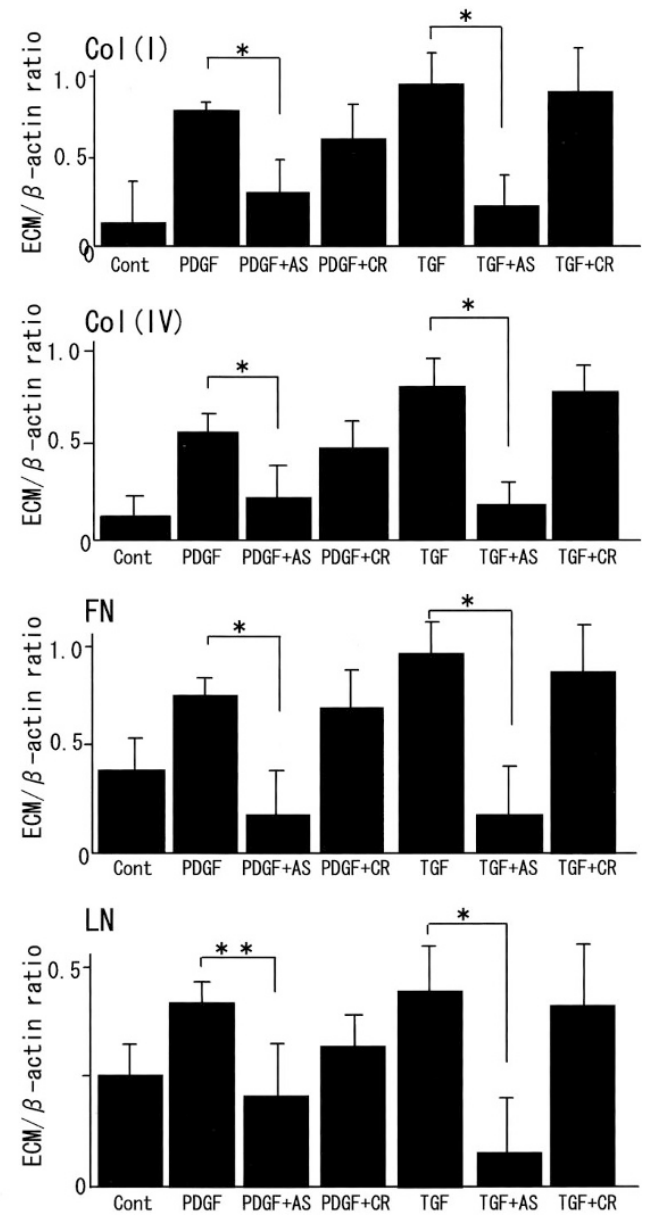

Figure 6.

Effects of an antisense oligodeoxynucleotide (ODN) on extracellular matrix (ECM) protein synthesis in the PDGF-BB- or TGF- $\beta$-stimulated cultured rat parietal epithelial cell (PEC) line. (A) The connective tissue growth factor (CTGF) antisense ODN considerably blocks endogenous CTGF mRNA in the growth factor-stimulated PEC line. $A S=$ antisense ODN, CR = control-reverse ODN. (B) Western blotting analyses for collagen types I and IV, fibronectin, and laminin. The CTGF AS ODN significantly diminishes the expression of all four ECM proteins; the effects are not apparent in CR ODN. Equivalent amounts (5 $\mu \mathrm{g} / \mathrm{lane}$ ) of each sample were analyzed. Western blotting was independently performed four times, and representative data from one experiment are shown. (C) Semiquantitative analysis of ECM protein expression as compared with $\beta$-actin. Values represent means \pm SD of four independent Western blotting analyses, and the statistical significance is ${ }^{*} p<0.01$ and ${ }^{* *} p<0.05$. The quantitative and statistical data are described in the text.

the evolution of crescents and subsequent scar formation.

To examine the roles of these growth factors in the cell proliferation or fibrogenic properties of ECM production, we used a rat PEC line. Although a number of glomerular epithelial cell lines have previously been reported (Harper et al, 1984; Quigg et al, 1988; Striker and Striker, 1985), the cellular phenotypes were not well identified (Holthofer et al, 1991; Norgaard, 1987; Weinstein et al, 1992; Yaoita et al, 2001). In this context, our cell line uniformly expressed pancadherin, WT1, Pax-2, cytokeratin, and vimentin. Since WT1 is, to some extent, localized in proliferating PECs in S-shaped bodies, WT1 expression in this cell line is not inconsistent with proliferating PECs. In addition, PGP9.5, recently recognized as a specific PEC marker, was also expressed (Shirato et al, 2000). Moreover, the podocyte-specific markers synaptopodin and podocalyxin were virtually negative. We excluded tubular and endothelial origins by confirming negative staining for peanut lectin and von Willebrand factor, respectively. Thus, this cell line is very likely to have the PEC phenotype.

Takeuchi et al (1992) reported that FGF-2 exerted a proliferative effect on their cultured glomerular epithelial cell line having a cobblestone-like polygonal shape. The present study showed that both FGF-2 and PDGF-BB stimulated the incorporation of $\left[{ }^{3} \mathrm{H}\right]$ thymidine into the rat PEC line. However, FGF-2 induced a more pronounced uptake than PDGF-BB, even at a low dose. Hence, it may be surmised that both FGF-2 and PDGF-BB promote the proliferation of the PECs responsible for the formation of cellular crescents.

Cellular crescents often result in fibrous scars that determine the glomerular fate. Inhibition of cell proliferation, reduction in the cell number by apoptosis, and ECM deposition are the biological bases for the process of scarring (Shankland, 1997; Shimizu et al, 1996). We have previously reported that the expression of p27, a cell cycle inhibitor, was diminished in cellular crescents (Nitta et al, 1999). Fujigaki and co-workers (2001) showed that p27 
expression was increased in fibrocellular crescents in a rat CRGN. From these observations in vivo, it may be surmised that the re-expression of p27 is involved in the cessation of cell proliferation in PECs and the subsequent fibrogenic processes. Our present results showed that the rat PEC line increased ECM protein synthesis in parallel with the up-regulation of p27 and CTGF, and downregulation of CDK2. Interestingly, a recent report by Abdel-Wahab et al (2002) showed that recombinant CTGF up-regulated p27 expression in mesangial cells and that TGF- $\beta$-mediated p27 upregulation was CTGF dependent. Thus, it may be that in crescents CTGF up-regulates p27 resulting in cell cycle arrest and leading to excessive ECM synthesis.

The regulatory mechanism for CTGF in cellular crescents needs to be determined. It is well accepted that CTGF expression is strongly induced by TGF- $\beta$ in various tissues (Dammeier et al, 1998; di Mola et al, 1999; Hong et al, 1999; Rachfal and Brigstock, 2003; Razzaque et al, 2003). Likewise, in the kidney, CTGF promoted renal fibrosis under TGF- $\beta$ stimulation in Thy- 1 nephritis and diabetic nephropathy (Ito et al, 2001; Murphy et al, 1999). In vitro studies showed that TGF- $\beta$ increased CTGF expression in the mesangial cells, proximal tubular cells, and renal fibroblasts (Blom et al, 2001; Chen et al, 2002; Heusinger-Ribeiro et al, 2001; Riser et al, 2000; Wang et al, 2001; Yokoi et al, 2002). In this context, the present study first demonstrates that CTGF acts on ECM production in PECs under stimulation with not only TGF- $\beta$ but also PDGF-BB. In addition, CTGF antisense ODN significantly diminished ECM protein synthesis in the TGF- $\beta$ - or PDGF-BB-stimulated rat PEC line. Recently, it has been shown that PDGF receptor-B and TGF- $\beta$ receptors are localized in glomerular crescents (Fujigaki et al, 2001; Matsuda et al, 1997). In cellular or fibrocellular crescents, PDGF-BB is surmised to be increased by secretion from infiltrating macrophages, injured podocytes, mesangial cells, and PECs (Floege et al, 1993; Gesualdo et al, 1991). These findings may partly explain the fibrogenic mechanisms in the glomerular crescents via the CTGF pathway. Because mechanical stretching and hypoxia (Keil et al, 2002; Schild and Tryeb, 2002) induce CTGF in mesangial cells and lung fibroblasts, respectively, various other factors are also likely involved in the scarring process in crescents.

In summary, CTGF mRNA is localized in the PECs, but not macrophages, in the cellular and fibrocellular crescents. In the PEC line, both TGF- $\beta$ and PDGF-BB accelerated ECM synthesis accompanied by CTGF up-regulation, and blocking CTGF diminished such growth factor-mediated ECM production. Thus, CTGF is an important mediator of the scarring process in the glomerular crescents. Our study sheds light on a novel therapeutic strategy for the crescent formation of glomerulonephritis by blocking CTGF.

\section{Materials and Methods}

\section{Animal Model of CRGN}

Twenty-six male Wistar Kyoto rats (Charles River Japan, Yokohama, Japan), each weighing $100 \mathrm{~g}$, were used. CRGN was induced in 15 rats with a single injection of $50 \mu \mathrm{l}$ of rabbit antirat GBM antiserum (kindly provided by Dr. Yamamoto, Niigata University, Japan). The rats were divided into three groups (Kawasaki et al, 1992). Another 11 rats were each given a single injection of normal saline as a control and then divided into three groups. Experimental and control rats were anesthetized and perfused with $4 \%$ paraformaldehyde in PBS on Days 4, 7, and 14. The renal tissues were fixed in the same fixative, and embedded in paraffin or snap-frozen and stored at $-80^{\circ} \mathrm{C}$ until use. All experiments were performed according to the guidelines for the care and use of laboratory animals at the University of Tsukuba.

\section{In Situ Hybridization and Immunohistochemistry}

A 540-bp cDNA fragment of rat CTGF (GenBank gi5070343 496-1037) was amplified by PCR using sense and antisense primers 5'-GCGTGTGCACTGCCAAAGAT-3' and 5'-TAATACGACTCACTATAGCAGCCAGAAAGCTCAAACTTGA-3', respectively. The amplicon was cloned in the pCR2.1-TOPO vector (Invitrogen, Breda, the Netherlands). In vitro transcription of the purified insert was performed using T7 RNA polymerase and digoxigenin (DIG)-conjugated UTP (Roche, Mannheim, Germany) to produce DIG-labeled antisense riboprobes. Four- $\mu \mathrm{m}$-thick sections of paraffin-embedded renal tissue were deparaffinized and digested with $10 \mu \mathrm{g} / \mathrm{ml}$ proteinase $\mathrm{K}$ (WAKO, Osaka, Japan) for 10 minutes at $37^{\circ} \mathrm{C}$. DIG-labeled riboprobes ( $1 \mu \mathrm{g} / \mathrm{ml}$ ) were then added to a hybridization solution containing $50 \%$ deionized formamide, $5 \times$ SSC, $1 \%$ SDS, $50 \mu \mathrm{g} / \mathrm{ml}$ heparin, and $50 \mu \mathrm{g} / \mathrm{ml}$ yeast RNA (Roche). Hybridization was performed for 18 hours at $50^{\circ} \mathrm{C}$. Thereafter, the slides were washed once with $5 \times$ SSC containing $50 \%$ formamide and twice with $2 \times \mathrm{SSC}$ for 30 minutes at $50^{\circ} \mathrm{C}$. Sections were then blocked with $0.5 \%$ blocking reagent (Roche), and incubated with alkaline phosphataseconjugated Fab fragments of a sheep anti-DIG antibody (Roche) at a dilution of 1:750 for 16 hours at $4^{\circ} \mathrm{C}$. Bound alkaline phosphatase activity was visualized with nitroblue tetrazolium chloride and 5-bromo4-chloro-3-indolyl phosphate (NBT/BCIP, Roche).

Immunohistochemistry was performed on 4- $\mu \mathrm{m}-$ thick paraffin sections to detect synaptopodin (antisynaptopodin antibody, 1:2, G1D4; Progen, Heidelberg, Germany) and macrophages (anti-ED1 antibody, 1:500; Serotec, Oxford, United Kingdom). After blocking with $10 \%$ normal rabbit serum, sections were incubated with the primary antibody for 16 hours at $4^{\circ} \mathrm{C}$. Immunoreaction products were detected using an avidin-biotin-peroxidase complex (SAB-PO Kit, Nichirei, Tokyo, Japan) and 3'3-diaminobenzidine. Counter-staining was performed with hematoxylin. 
Immunofluorescence was performed on 4- $\mu$ m-thick frozen sections to examine the expression of pancadherin (anti-pan-cadherin, 1:1000, CH-19; Sigma, St. Louis, Missouri), which was used as an epithelial marker. After blocking with 5\% normal goat serum, sections were incubated with the primary antibody for 60 minutes at room temperature. They were then washed and incubated for 30 minutes at room temperature with FITC-conjugated rabbit antimouse IgG antibody (1:200, Cappel, Aurora, Ohio), followed by visualization by immunofluorescence using a phasecontrast microscope (AX-70; Olympus, Tokyo, Japan).

\section{Pathological Analysis}

Paraffin sections were stained with hematoxylin and eosin and methenamine silver to distinguish cellular and fibrocellular crescents. Glomeruli were considered to exhibit crescent formation when at least two layers of cells were observed in the Bowman's space. The number of crescents was counted in at least 300 glomeruli per rat and expressed as the mean percentage of each group. The CTGF mRNA and ED1 scores ( 0 , negative; $1,+; 2,++$, according to the staining intensity) were estimated in each of at least 50 crescents counted per rat.

\section{Cell Culture}

The rat glomerular parietal epithelial cell line (PEC line) was established by the method devised by Harper and co-workers (1984), with some modifications. Cell clones were proliferated with K1-3T3 medium (Quigg et al, 1988), and cells between the 20th and 30th passage were used for the study. To analyze the association between ECM protein synthesis and cell proliferation activity in the PEC line by Western blotting analysis (method described below), we divided the cell proliferation condition into three segments (nonconfluent: $0.5 \pm 0.12 \times 10^{4}$ cells $/ \mathrm{cm}^{3}$, subconfluent: $1.0 \pm 0.15 \times 10^{4}$ cells $/ \mathrm{cm}^{3}$, and fully confluent: $2.0 \pm 0.18 \times 10^{4}$ cells $\left./ \mathrm{cm}^{3}\right)$.

\section{Characterization of the Rat PEC Line}

Cells on glass slides were blocked in $10 \%$ normal goat serum for 60 minutes. The primary antibodies were added at an optimal dilution for 90 minutes. The antibodies used were anti-pan-cadherin (1:300), antiWT1 (1:100, C-19, Santa Cruz Biotechnology, Santa Cruz, California), anti-Pax-2 (1:200, Z-RX-2, Zymed, San Francisco, California), anti-vimentin (1:100, V9, Sigma), anti-pan-cytokeratin (1:100, C2562, Sigma), anti-synaptopodin (1:100), anti-podocalyxin (1:100, $5 \mathrm{~A}$, a generous gift from Dr. Miettinen), anti-PGP9.5 (1:100, 13C4, Biogenesis, New Fields, United Kingdom), anti-von Willebrand factor (1:300, DAKO, Kyoto, Japan), and peanut lectin (1:200, FITC-labeled, Sig$\mathrm{ma})$. The cells were then incubated for 30 minutes with FITC- or RITC-conjugated goat antimouse or antirabbit IgG antibodies (1:100, Cappel). A negative control was prepared using PBS instead of the primary anti- bodies. The cells were then examined under a fluorescence microscope.

\section{Cell Proliferation Assay}

A $\left[{ }^{3} \mathrm{H}\right]$ thymidine incorporation study was applied to estimate cell proliferation. Briefly, cells were plated in 24 -well plates at a density of $2 \times 10^{4}$ cells/well. Cells were grown to subconfluency in medium containing $10 \%$ FCS, and subsequently starved for 24 hours in FCS-free medium to render the cells quiescent. Cells were then stimulated with recombinant human (rh) FGF-2 (Progen) or rh PDGF-BB (Sigma) at different concentrations $(0,2.5,5,10,20$, and $50 \mathrm{ng} / \mathrm{ml})$ for 24 hours. For the determination of $\left[{ }^{3} \mathrm{H}\right]$ thymidine uptake, cells were stimulated with $2 \mu \mathrm{Ci} / \mathrm{ml}$ methyl$\left[{ }^{3} \mathrm{H}\right]$ thymidine (NET-027Z, NEN, Tokyo, Japan) for 6 hours, and then incubated in $500 \mu \mathrm{l}$ of ice-cold $10 \%$ trichloroacetic acid for 20 minutes. After incubation with $200 \mu \mathrm{l}$ of $1 \mathrm{M} \mathrm{NaOH}$, the cell lysates were transferred to scintillation vials. After adding $5 \mathrm{ml}$ of liquid scintillator (Clear-sol I, Nacalai Tesque, Kyoto, Japan), the incorporation was measured with a liquid scintillation counter (Beckman Coulter, Tokyo, Japan). Cell proliferation assays were independently repeated four times.

\section{Western Blotting}

Cells were grown to subconfluency in medium containing 10\% FCS and subsequently starved for 24 hours in FCS-free medium. Cells were then stimulated with 5 and $10 \mathrm{ng} / \mathrm{ml}$ rh FGF-2, rh PDGF-BB, or rh TGF- $\beta$ (R\&D Systems, Minneapolis, Minnesota) for 24 hours. Cells were lysed at $4^{\circ} \mathrm{C}$ in a lysis buffer composed of $50 \mathrm{~mm}$ Tris- $\mathrm{HCl}$ [pH 7.5] containing 20 mM HEPES, $250 \mathrm{~mm}$ sucrose, 1\% Triton X-100, 2 $\mu \mathrm{g} / \mathrm{ml}$ aprotinin (WAKO), and $1 \mathrm{~mm}$ PMSF (Sigma). Following ultrasonic vortexing, the cell lysates were dissolved by boiling in the presence of SDS and 2-mercaptoethanol. Protein estimation was performed with a DC Protein Assay Kit (Bio-Rad, Tokyo, Japan). Five micrograms of reduced samples were subjected to electrophoresis in a $10 \%$ SDS-polyacrylamide gel and electrophoretically transferred to a nitrocellulose membrane. After blocking with PBST containing 5\% nonfat skim milk, the membranes were incubated with one of the following antibodies: goat anti-collagen type I (1:1000, Southern Biotechnology, Birmingham, Alabama), goat anti-collagen type IV (1:1000, Southern Biotechnology), rabbit antihuman fibronectin (1:1000, Cappel), rabbit antirat laminin (1:1000, DAKO), anti-p27 (1:1000, clone57, BD Biosciences, Franklin Lakes, New Jersey), or anti-CDK2 (1:1000, M2, Santa Cruz Biotechnology). Incubation was carried out in a blocking buffer overnight at $4^{\circ} \mathrm{C}$. Subsequent incubation was carried out with peroxidaseconjugated donkey antirabbit lgG (1:5000, Amersham, Buckinghamshire, United Kingdom), goat antimouse IgG (1:5000, Amersham), or rabbit antigoat IgG (1:5000, Zymed). The blots were developed using ECL plus Western blotting detection reagents (Amersham). 
Equality of loading was ensured by testing for $\beta$-actin using an anti- $\beta$-actin antibody (1:2000, AC-15, Sigma). Blots were scanned and analyzed with $\mathrm{NIH}$ Image 1.55. Signal intensities in control lanes were arbitrarily assigned a value of 1.00. The Western blotting analysis was independently repeated four times with qualitatively similar results.

\section{RNA Extraction and RT-PCR}

Total RNA was extracted from the PEC line by a standard procedure using Trizol reagent (Invitrogen Corporation, Carlsbad, California). One microgram of total RNA was used for RT by cloned MMLV-RT (Invitrogen) and oligo-dT ${ }^{12-18}$ primer (Invitrogen) at $37^{\circ} \mathrm{C}$ for 1 hour. The single stranded cDNA product was denatured at $94^{\circ} \mathrm{C}$ and amplified by PCR with two primers in three steps: denaturation at $94^{\circ} \mathrm{C}$ for 1 minute, annealing for 1 minute, and elongation at $72^{\circ} \mathrm{C}$ for 1 minute. PCR was performed for 23 cycles for GAPDH, and 24 cycles for CTGF and p27, such that all products could be assayed in the exponential phase of the amplicon curve in a thermal cycler (Bio-Rad). The primers used were as follows: rat p27 (5' to $3^{\prime}$, product $752 \mathrm{bp}, \mathrm{Tm} 62^{\circ} \mathrm{C}$ ) GGCGTTTCGCTITTGTTTGG and GCTTCATAAAGCAGTGATGT; rat CTGF (5' to $3^{\prime}$, product $527 \mathrm{bp}, \mathrm{Tm} 55^{\circ} \mathrm{C}$ ) AGAACTGTGCACGGAGCGTG and CCTGACCATTCAGAGACGAC; and rat GAPDH (5' to $3^{\prime}$, product 298bp, Tm 55 C) TCCCTCAAGATTGTCAGCAA and AGATCCACAACGGATACATT. The PCR products were separated by $2 \%$ agarose gel electrophoresis and visualized with ethidium bromide. Each experiment was accompanied by the amplification of GAPDH as an internal control, and the intensities of the cDNA bands were corrected for the GAPDH band intensities. RT-PCR was independently repeated four times for the semiquantitative analysis.

\section{Effects of a CTGF Antisense Oligonucleotide on the Rat PEC Line}

A rat CTGF ODN was constructed with a 18mer derived from the starting translation site, which contained the initial ATG. The sequences were as follows: CTGF antisense ODN, 5'- GACGGAGGCGAGCATGGT -3'; and control reverse ODN, 5'- TGGTACGAGCGGAGGCAG -3' (Yokoi et al, 2001). Synthetic ODN was added directly to the serum-free culture medium (final concentration, $20 \mu \mathrm{g} / \mathrm{ml}$ ) in the presence or absence of TGF- $\beta$ (10 ng/ml) or PDGF-BB (20 $\mathrm{ng} / \mathrm{ml}$ ) for 24 hours. We examined the effects of the ODN by confirming the rat CTGF mRNA levels by RT-PCR and the amount of ECM proteins by Western blotting analysis.

\section{Statistical Analysis}

The results are presented as the means \pm SD. Fisher's PLSD test was used to compare the data. Differences were considered significant at $p<0.01$. (Pawar et al, 1995)

\section{Acknowledgements}

We would like to thank Dr. Miettinen for providing the 5A antibody, Drs. E. Yaoita and T. Yamamoto for providing the rabbit antirat GBM antiserum, and Dr. Alison Sherwin of Edanz Editing Ltd. for editing the manuscript.

\section{References}

Abdel-Wahab N, Weston BS, Roberts T, and Mason RM (2002). Connective tissue growth factor and regulation of the mesangial cell cycle: Role in cellular hypertrophy. J Am Soc Nephrol 13:2437-2445.

Alpers CE, Seifert RA, Hudkins KL, Johnson RJ, and BowenPope DF (1993). PDGF-receptor localizes to mesangial, parietal epithelial, and interstitial cells in human and primate kidneys. Kidney Int 43:286-294.

Blom IE, Dijk AJ, Wieten L, Duran K, Ito Y, Kleij L, de Nichilo M, Rabelink TJ, Weening JJ, Aten J, and Goldschmeding R (2001). In vitro evidence for differential involvement of CTGF, TGF $\beta$, and PDGF-BB in mesangial response to injury. Nephrol Dial Transplant 16:1139-1148.

Bork P (1993). The molecular architecture of a new family of growth regulators related to connective tissue growth factor. FEBS Lett 327:125-130.

Bradham DM, Igarashi A, Potter RL, and Grotendorst GR (1991). Connective tissue growth factor, a cysteine-rich mitogen secreted by human vascular endothelial cells is related to the SRC-induced immediate early gene product CEF-10. J Cell Biol 114:1285-1294.

Chen Y, Blom IE, Sa S, Goldschmeding R, Abraham DJ, and Leask A (2002). CTGF expression in mesangial cells: Involvement of SMADs, MAP kinase, and PKC. Kidney Int 62:11491159.

Dammeier J, Brauchle M, Falk W, Grotendorst GR, and Werner S (1998). Connective tissue growth factor: A novel regulator of mucosal repair and fibrosis in inflammatory bowel disease? Int J Biochem Cell Biol 30:909-922.

di Mola FF, Friess $H$, Martibnoni ME, Di Sebastiano P, Zimmermann A, Innocenti P, Graber H, Gold LI, Korc M, and Buchler MW (1999). Connective tissue growth factor is a regulator for fibrosis in human chronic pancreatitis. Ann Surg 230:63-71.

Floege J, Johnson RJ, Alpers CE, Fatemi-Nainie S, Richardson CA, Gordon K, and Couser WG (1993). Visceral glomerular epithelial cells can proliferate in vivo and synthesize platelet-derived growth factor B-chain. Am J Pathol 142:637650.

Floege J, Hudkins KL, Eitner F, Cui Y, Morrison RS, Schelling MA, and Alpers CE (1999). Localization of fibroblast growth factor-2 (basic FGF) and FGF receptor-1 in adult human kidney. Kidney Int 56:883-897.

Fujigaki Y, Sun DF, Fujimoto T, Suzuki T, Goto T, Yonemura K, Morioka T, Yaoita E, and Hishida A (2002). Mechanisms and kinetics of Bowman's epithelial-myofibroblast transdifferentiation in the formation of glomerular crescents. Nephron 92:203-212.

Fujigaki Y, Sun DF, Fujimoto T, Yonemura K, Morioka T, Yaoita E, and Hishida A (2001). Cytokines and cell cycle regulation in the fibrous progression of crescent formation in 
antiglomerular basement membrane nephritis of WKY rats. Virchows Arch 439:35-45.

Gesualdo L, Pinzani M, Floriano JJ, Hassan MO, Nagy NU, Schena FP, Emancipator SN, and Abboud HA (1991). Platelet-derived growth factor expression in mesangial proliferative glomerulonephritis. Lab Invest 65:160-167.

Guettier C, Nochy D, Jacquot C, Mandet C, Camilleri JP, and Bariety J (1986). Immunohistochemical demonstration of parietal epithelial cells and macrophages in human proliferative extra-capillary lesions. Virchows Arch 409:739-748.

Harper PA, Robinson JM, Hoover RL, Wright TC, and Karnovsky MJ (1984). Improved methods for culturing rat glomerular cells. Kidney Int 26:875-880.

Harrison DJ and Macdonald MK (1986). The origin of cells in the glomerular crescent investigated by the use of monoclonal antibodies. Histopathology 10:945-952.

Heusinger-Ribeiro J, Eberlein M, Abdel-Wahab N, and Goppelt-Struebe M (2001). Expression of connective tissue growth factor in human renal fibroblasts: Regulatory roles of Rho A and cAMP. J Am Soc Nephrol 12:1853-1861.

Holthofer H, Sainio K, and Miettinen A (1991). Rat glomerular epithelial cells do not express podocytic markers when cultured in vitro. Lab Invest 65:548-557.

Hong HH, Uzel MI, Duan C, Sheff MC, and Trackman PC (1999). Regulation of lysyl oxidase, collagen, and connective tissue growth factor by TGF-beta1 and detection in human gingiva. Lab Invest 79:1655-1657.

Ito Y, Aten J, Bende RJ, Oemer BS, Rabelink TJ, Weening JJ, and Goldschmeding R (1998). Expression of connective tissue factor in human renal fibrosis. Kidney Int 53:853-861.

Ito Y, Goldschmeding R, Bende RJ, Claessen N, Chand MA, Kleij L, Rabelink TJ, Weening JJ, and Aten J (2001). Kinetics of connective tissue growth factor expression during experimental proliferative glomerulonephritis. J Am Soc Nephrol 12:472-484.

Jennette JC (1998). Crescentic glomerulonephritis. In: Jennette JC, Olson JL, Schwartz MM, and Silva FG, editors. Heptinstall's Pathology of the Kidney. Philadelphia: Lippincott-Raven Ltd., 625-656.

Kawasaki K, Yaoita E, Yamamoto T, and Kihara I (1992). Depletion of CD8 positive cells in nephrotoxic serum nephritis of WKY rats. Kidney Int 41:1517-1526.

Keil A, Blom IE, Goldschmeding R, and Rupprecht HD (2002). Nitric oxide down-regulates connective tissue growth factor in rat mesangial cells. Kidney Int 62:401-411.

Kondo Y, Shigematsu H, and Kobayashi Y (1972). Cellular aspects of rabbit Masugi nephritis. II. Progressive glomerular injuries with crescent formation Lab Invest 27:620-631.

Lianos EA, Liu J, and Guglielmi K (1997). Quantification of changes in transforming growth factor-beta 1 gene expression in experimental crescentic glomerulonephritis. Proc Soc Exp Biol Med 214:180-186.

Magil AB (1985). Histogenesis of glomerular crescents. Immunohistochemical demonstration of cytokeratin in crescent cells. Am J Pathol 120:222-229.

Matsuda M, Shikata K, Makino H, Sugimoto H, Ota K, Akiyama K, Hirata K, and Ota Z (1997). Gene expression of PDGF and PDGF receptor in various forms of glomerulonephritis. Am J Nephrol 17:25-31.
Morrin PA, Hinglais, Nagarra B, and Kreis H (1978). Rapidly progressive glomerulonephritis. A clinical and pathologic study. Am J Med 65:446-460.

Murphy M, Godson C, Cannon S, Kato S, Mackenzie HS, Martin F, and Brady HR (1999). Suppression subtractive hybridization identifies high glucose levels as a stimulus for expression of connective tissue growth factor and other genes in human mesangial cells. J Biol Chem 274:58305834 .

Nagata M (2000). Pathogenesis of glomerulosclerosis: Role of epithelial interactions. Clin Exp Nephrol 4:173-181.

$\mathrm{Ng}$ YY, Fan JM, Mu W, Nikolic-Peterson DJ, Yang WC, Huang TP, Atkins RC, and Lan HY (1999). Glomerular epithelial-myofibroblast transdifferentiation in the evolution of glomerular crescent formation. Nephrol Dial Transplant 14:2860-2872.

Nitta K, Horita S, Honda K, Uchida K, Watanabe T, Nihei H, and Nagata M (1999). Glomerular expression of cell-cycleregulatory proteins in human crescentic glomerulonephritis. Virchows Arch 435:422-427.

Norgaard JOR (1987). Rat glomerular epithelial cells in culture: Parietal or visceral epithelial origin? Lab Invest 57: 277-290.

Pawar S, Kartha S, and Toback FG (1995). Differential gene expression in migrating renal epithelial cells after wounding. J Cell Physiol 165:556-565.

Quigg RJ, Cybulsky AV, Jacobs JB, and Salant DJ (1988). Anti-Fx1A produces complement-dependent cytotoxicity of glomerular epithelial cells. Kidney Int 34:43-52.

Rachfal AW and Brigstock DR (2003). Connective tissue growth factor in hepatic fibrosis. Hepatol Res 26:1-9.

Razzaque MS, Foster CS, and Ahmed AR (2003). Role of connective tissue growth factor in the pathogenesis of conjunctival scarring in ocular cicatrical pemphigoid. Invest Ophthalmol Vis Sci 44:1998-2003.

Riser BL, Denichilo M, Cortes P, Baker C, Grondin JM, Yee J, and Narins RG (2000). Regulation of connective tissue growth factor activity in cultured rat mesangial cells and its expression in experimental diabetic glomerulonephritis. J Am Soc Nephrol 11:25-38.

Sasaki T, Jyo Y, Tanda N, Kawakami Y, Nohno T, Tamai H, and Osawa G (1997). Changes in glomerular epithelial cells induced by FGF-2 and FGF-2 neutralizing antibody in puromycin aminonucleoside nephropathy. Kidney Int 51:301-309.

Schild C and Tryeb B (2002). Mechanical stress is required for high-level expression of connective tissue growth factor. Exp Cell Res 274:83-91.

Shankland ST (1997). Cell-cycle control and renal disease. Kidney Int 52:294-308.

Shimizu A, Masuda $Y$, Kitamura $H$, Ishizaki M, Sugisaki $Y$, and Yamanaka N (1996). Apoptosis in progressive crescentic glomerulonephritis. Lab Invest 74:941-951.

Shirato I, Asanuma K, Takeda Y, Hayashi K, and Tomino Y (2000). Protein gene product 9.5 is selectively localized in parietal epithelial cells of Bowman's capsule in the rat kidney. J Am Soc Nephrol 11:2381-2386.

Striker GE and Striker LJ (1985). Biology of disease. Glomerular cell culture. Lab Invest 53:122-131. 
Takeuchi A, Yoshizawa N, Yamamoto M, Sawasaki Y, Oda T, Sendo A, Niwa H, and Fuse Y (1992). Basic fibroblast growth factor promotes proliferation of rat glomerular visceral epithelial cells in vitro. Am J Pathol 141:107-116.

Wang S, Denichilo M, Brubaker C, and Hirschberg R (2001). Connective tissue growth factor in tubulointerstitial injury of diabetic nephropathy. Kidney Int 60:96-105.

Weinstein T, Cameron R, Kats A, and Silverman M (1992). Rat glomerular epithelial cells in culture express characteristics of parietal, not visceral, epithelium. J Am Soc Nephrol 3:12791287.

Whitworth JA, Morel-Maroger L, Mignon F, and Richet G (1976). The significance of extracapillary proliferation. Clinicopathological review of 60 patients. Nephron 16:1-19.

Yamamoto T, Watanabe T, Ikegaya N, Fujigaki Y, Matui K, Masaoka H, Nagase M, and Hishida A (1998). Expression of types I, II, and III TGF- $\beta$ receptors in human glomerulonephritis. J Am Soc Nephrol 9:2253-2261.
Yaoita E, Kurihara H, Sakai T, Ohshiro K, and Yamamoto T (2001). Phenotypic modulation of parietal epithelial cells of Bowman's capsule in culture. Cell Tissue Res 304:339-349.

Yokoi H, Mukoyama M, Sugawara A, Mori K, Nagae T, Makino H, Suganami T, Yahata K, Fujinaga Y, Tanaka I, and Nakao K (2002). Role of connective tissue growth factor in fibronectin expression and tubulointerstitial fibrosis. Am J Physiol Renal Physiol 282:F933-F942.

Yokoi H, Sugawara A, Mukoyama M, Mori K, Makino H, Suganami T, Nagae T, Yahata K, Fujinaga Y, Tanaka I, and Nakao K (2001). Role of connective tissue growth factor in profibrotic action of transforming growth factor- $\beta$ : A potential target for preventing renal fibrosis. Am J Kidney Dis 38: S134-S138.

Yoshioka K, Takemura T, Akano N, Miyamoto H, Iseki T, and Maki S (1987). Cellular and non-cellular compositions of crescents in human glomerulonephritis. Kidney Int 32:284291. 